Strahlenther Onkol 2014 • 190:602-603

DOI 10.1007/s00066-014-0674-5

Online publiziert: 29. April 2014

(c) Springer-Verlag Berlin Heidelberg 2014
József Lövey ${ }^{1} \cdot$ Rolf Sauer $^{2}$

${ }^{1}$ National Institute of Oncology, Budapest, Hungary

${ }^{2}$ Erlangen, Deutschland

\title{
Zum Gedenken an Professor Dr. György Nemeth (1935-2014)
}

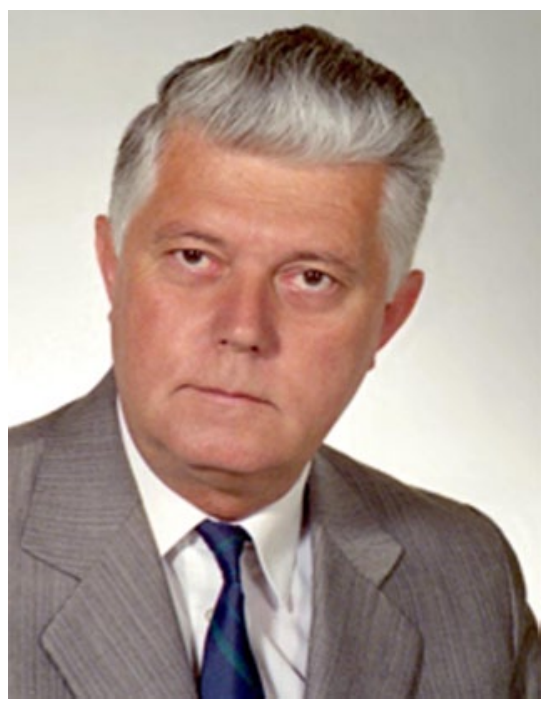

$\Delta$ Professor Dr. György Nemeth (Mit freundlicher Genehmigung National Institute of Oncology, Budapest)

Die Strahlentherapeutische und Onkologische Gesellschaft Ungarns hat mit dem plötzlichen Ableben von Herrn Professor Dr. med. György Nemeth einen herben und unüberwindlichen Verlust erlitten. Im 79. Lebensjahr ging er still und unerwartet von uns. Wir alle, die wir 20, 30, ja bis zu 40 Jahre lang seine Mitarbeiter gewesen waren, dachten immer, dass er ewig bei uns bliebe. Sein Fortgang ist unfassbar für uns und hinterlässt eine nicht auszufüllende Lücke. György Nemeth war der Nestor der ungarischen Radioonkologie.

György Nemeth promovierte 1960 mit ,summa cum laude‘ an der Medizinischen Universität von Budapest. Seine ärztliche Karriere startete er im Uzsoki-Krankenhaus (Fövárosi Onkoradiológiai Institut), wo er auch sein Fachdiplom für „Onkoradiologie“ und „Klinische Onkologie“ erhielt. Seine wissenschaftliche Arbeit be- gann er 1970 an der Berliner HumboldtUniversität, seinen akademischen Doktortitel erwarb er 1987 im Budapest.

An das Fövárosi Onkoradiológiai Institut wurde er 1964 als Leitender Arzt berufen, wo er dann von 1978-1992 als dessen Chefarzt tätig war. Von 1981-1987 war György Nemeth ehrenamtlicher und von 1987 an ordentlicher Universitätsprofessor. Er unterrichtete in Heidelberg und Budapest (OTE-HIETE-SOTE). Ab 1992 war er im National Institut für Onkologie in Budapest zunächst als Chefarzt für Radioonkologie tätig und erhielt den ersten Lehrstuhl für Radioonkologie in ganz Ungarn. Bis 2002 war er dort, vor allem als er Klinischer Direktor des gesamten National Institut für Onkologie wurde, einer der einflussreichsten Persönlichkeiten in Budapest überhaupt, beispielsweise als onkologischer Fachberater der Regierungsbehörden.

Prof. György Nemeth wurden bereits vor dem Fall des „Eisernen Vorhangs“ sowie danach unzählige Studienreisen ins westliche Ausland gestattet, womit er auch zahlreichen Einladungen nachkommen konnte. Dafür einige Beispiele: WHO-Stipendium nach Japan (1966), Hospitant an der Humboldt-Universität Berlin (1966-1967), MTA-NAS-Stipendium in die USA (1981), Humboldt-Stipendium (1972-1973 und 1985-1986) für den wissenschaftlichen Austausch an der Radiologischen Klinik im Heidelberg und eine Gastprofessur in Heidelberg (19881989). Prof. Nemeth war auch ordentliches Mitglied bzw. Ehrenmitglied in zahlreichen Fachgesellschaften des In- und Auslands. Von 1984-1992 war er Präsident der Onkologischen Fachaufsicht für die ungarische Hauptstadt. Im Jahr 1992 gründete er die Ungarische Gesell- schaft für Strahlentherapie und Onkologie, deren Präsident er bis 1996 war und von da an ihr Ehrenpräsident. Er präsidierte das Kollegium für Strahlentherapie und Onkologie bis 2001. 1995 vereinbarten Prof. György Nemeth und Prof. Rolf Sauer, dem Schriftleiter der ehrwürdigen Zeitschrift Strahlentherapie und Onkologie, in Budapest, dass dieses Journal auch offizielles Publikationsorgan der Ungarischen Gesellschaft für Strahlentherapie und Onkologie sein werde. Nemeth verfasste mehr als 300 Fachpublikationen und war Autor bzw. Koautor von 13 Fachbüchern.

Die ärztliche, wissenschaftliche und berufspolitische Tätigkeit von György Nemeth wurde mehrfach öffentlich anerkannt, beispielsweise durch die Verleihung des Madzsar-József-Preises, der Krompecher Ödön-Medaille, des Batthyany-Stratmann-Preises, des Ungarischen Vaterländischen Verdienstkreuzes, des Markusovszky-Preises, der Vándor-Ferenc-Medaille und des Pro-Patienten-Preises. Diese Zeichen der Anerkennung von Prof. Nemeth galten in weiten Kreisen dem geborenen Kliniker, dem verantwortungsvollen, fantastischen Arzt, aber auch dem weitblickenden Strategen, der über Jahrzehnte die Entwicklung der ungarischen Strahlentherapie bestimmt hat.

Wie nur wenigen war es Prof. György Nemeth vergönnt, zwei radioonkologische Schulen zu gründen, zuerst das Uzsoki-Spital, später das National Institut für Onkologie. Damit versicherte er sich doppelt, uns auch nach seinem Abgang in den Ruhestand weiterhin zur Verfügung $\mathrm{zu}$ stehen. All sein während eines langen fruchtbaren Lebens weitergegebenes, unschätzbares Wissen als Arzt und väterli- 
cher Freund lebt in seinen Schülern fort. György Nemeth ruhe in Frieden - requiescat in pacem!

József Lövey, Budapest, und

Rolf Sauer, Erlangen

\section{Korrespondenzadresse}

\section{Dr. J. Lövey}

National Institute of Oncology Ráth György u. 7-9, 1121 Budapest

lovey@oncol.hu 